\title{
Infrared welding of cross-linkable polyamide 66
}

\author{
C. Leisen*, D. Drummer \\ Friedrich-Alexander-Universität Erlangen-Nürnberg (FAU), Faculty of Engineering, Department of Mechanical \\ Engineering, Institute of Polymer Technology, Am Weichselgarten 9, 91058 Erlangen, Germany
}

Received 23 February 2016; accepted in revised form 5 June 2016

\begin{abstract}
Radiation cross-linking of polyamide 66 with electron beams alters the material's characteristics. This leads to a varied relationship amongst the process, structure, and properties for infrared welding cross-linked polyamide 66. A threedimensional network of covalent bonds results in an impeded melt flow and altered welding characteristics. Compared to non-cross linked polyamide, a changed energy input in the weld during infrared heating and a reduced meltdown can be observed. Such thermal developments and a reduced meltdown affect the resulting weld strengths. Welding factors of almost $60 \%$ of base material strengths can be achieved. A clear influence of the heating time on the weld strength can be observed. The scope of this article is to investigate the influence of radiation cross-linking on the material characteristics and, by extension, the resulting processing and welding characteristics. Mechanical and optical investigations serve to highlight the influence of radiation cross-linking on the infrared welding process of polyamide 66.
\end{abstract}

Keywords: mechanical properties, cross-linking, polymer welding, infrared welding, polyamide 66

\section{Introduction}

\subsection{Radiation cross-linking of polyamide 66}

Radiation cross-linking is a well-known and established technique for enhancing the properties of thermoplastic polymers. Typical radiation sources are gamma rays, electron beams and X-rays [1]. The radiation induced cross-links between the macromolecules lead to improved physical properties and allow a wide range of industrial applications like for example pipes and tubes, hip joint pans, foams, shrinking-fit products or automotive applications [1-3]. In 1952, Charlesby described the influence of radiation on the properties of polyethylene for the first time [4, 5]. Subsequent investigations extended the knowledge about radiation cross-linking and the possible material range [6].

The process of cross-linking can be divided into two main reactions. High-energy radiation transfers energy to the atoms and results in an ionization or excitation of the atoms during the primary reaction $[1$,
2]. Further reactions lead to the formation of radicals. These radicals enable cross-linking of the polymer in its amorphous region in a secondary reaction $[1,2]$. Aside from the formation of covalent bonds, degradation, chain scission and oxidation can occur, possibly causing the material properties to deteriorate [1].

The resulting three dimensional covalent networks between the macromolecules results in an increase in the short-term temperature resistance and a rubbery-elastic behavior above the crystallite melting temperature, Figure $1[7,8]$. These covalent bonds also influence the melting and crystallization behavior towards lower temperatures $[1,3,8,9]$. Aside from polyethylene, other polymers, such as polyamide, can be cross-linked by high energy radiation [6]. In order to attain economical radiation exposure rates, cross-linking agents are needed. These polyfunctional monomers, e.g. triallyl isocyanurate (TAIC), allow a cross-linking at lower and economical radiation 


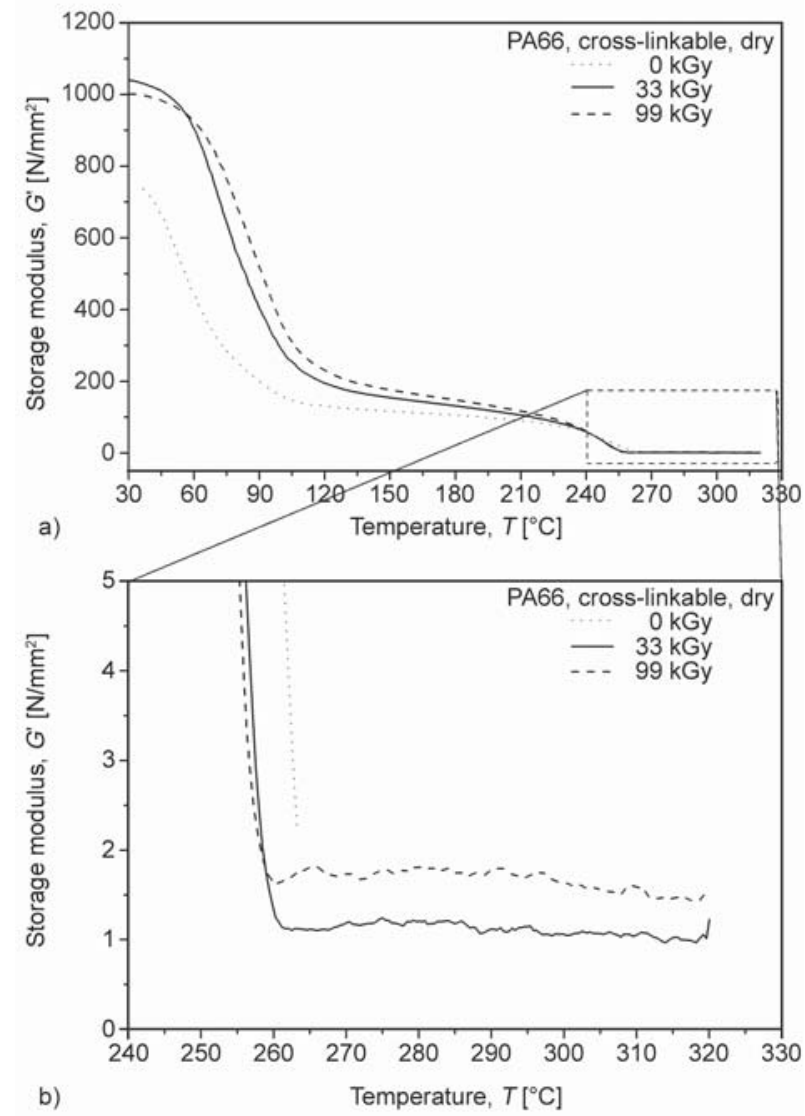

Figure 1. Residual stiffness of radiation cross-linkable, polyamide 66 (DMA) [7]: (a) complete temperature range, (b) within range of crystallite melting temperature

doses and temperatures [10-13]. Previous investigations into vibration welding of radiation cross-linked polyamide 66 have shown that cross-linking with its changed material properties leads to a varied relationship amongst the process, structure, and properties for vibration welding cross-linked polyamides $[7,14]$. Especially processing time and temperature influence the material characteristics of cross-linked polyamide [14]. It was shown that during vibration welding the energy input and the resulting weld temperature in the weld zone differs between the selected material and process settings and exhibits an in- consistency with the time [7]. These inconsistencies make it difficult to analyze the influence of the temperature during the joining process on the resulting welds. Therefore a joining technology with a homogenous energy input like infrared welding is used to investigate the influence of the temperature on the process, structure, and properties for welding crosslinked polyamides.

\subsection{Infrared welding}

Welding is an established way of joining polymer parts. The different welding technologies can be classified according to the heating method employed [15]. Technologies which use friction to heat up the joining area are for example vibration welding or friction stir spot welding. The oscillating movement of the joining partner relative to each other with a defined joining pressure is characteristic for vibration welding. Friction stir spot welding uses a rotating punch to heat up the joining partners. This process can be divided in the typical phases preheating, joining, consolidation, waiting and tool retraction $[16,17]$. Infrared welding is a welding technology that uses an infrared (IR) emitter to heat up the samples. Compared to other joining technologies, such as hot plate welding, the temperature in the joining zone is a function of the machine and material parameters [18]. Advantages of infrared welding are the contactless heating of the samples and the higher geometry freedom, compare to hot plate welding, vibration welding or stir spot welding.

The infrared emitters can be separated into short wavelength (near infrared), medium wavelength (near infrared) and long wavelength emitters (mid wavelength and far infrared), Table 1 [19-21].

These radiators emit electromagnetic radiation. The primary, effective radiation is infrared radiation with a maximum intensity dependent on the surface temperature of the radiator [22]. The emitted infrared

Table 1. Classification of infrared emitters and their wavelength, based on DIN 5030 part 2, DIN EN 60519-12 and DIN EN 62798 [19-21]

\begin{tabular}{|c|l|c|c|c|}
\hline IR-Radiation & \multicolumn{1}{|c|}{ Type } & $\begin{array}{c}\text { Wavelength } \\
{[\boldsymbol{\mu m}]}\end{array}$ & $\begin{array}{c}\text { Wave number } \\
{\left[\mathbf{c m}^{-\mathbf{1}}\right]}\end{array}$ & \multicolumn{1}{|c|}{ Examples of emitters } \\
\hline IR-A & $\begin{array}{l}\text { Short wavelength } \\
\text { (near infrared) }\end{array}$ & $0.78-1.4$ & $12821-7143$ & Halogen emitters \\
\hline IR-B & $\begin{array}{l}\text { Medium wavelength } \\
\text { (near infrared) }\end{array}$ & $1.4-3.00$ & $7143-3333$ & Metal foil emitters \\
\hline IR-C & $\begin{array}{l}\text { Long wavelength } \\
\text { (mid wavelength and far infrared) }\end{array}$ & $3.00-1000$ & $3333-10$ \\
\hline
\end{tabular}


light is, based on the optical properties of the irradiated material, partly reflected from the surface of the polymer [23]. This reduced radiation intensity penetrates the material and is either absorbed or transmitted [23].

The degree of absorption of the infrared light by the thermoplastic polymer depends on the wavelength as well as on the chemical and morphological structure of the polymer [23]. A characteristic absorption band for polymers is at a wavelength of $3.4 \mu \mathrm{m}$ (wavenumber $2941 \mathrm{~cm}^{-1}$ ) [18, 23]. This wavelength is characteristic for $[\mathrm{C}-H]_{\mathrm{n}}$ groups stretching vibrations $[23,24]$. Additives or fillers can also affect the absorption properties [18]. The crystalline structure of semi-crystalline polymers affects the transmission of the infrared light. The light is refracted and reflected on the boundary layer between amorphous and crystalline areas and spherulites. The optical penetration depth decreases at an increasing wavelength, which is caused by increasing scattering [23]. The resulting temperature level depends on the emission spectrum of the emitter and the absorption properties of the material [18].

Therefore, the scope of this article is to investigate the first time for radiation cross-linked polyamide; to what extent radiation dose, the resulting degree of crosslinking and heating time affect the resulting weld line's temperature during infrared welding and whether these parameters influence the weld strength of infrared-welded, cross-linked polyamide 66. Furthermore, these results shall be correlated with noncross-linked polyamide 66 .

\section{Experimental section}

\subsection{Materials and test specimens}

For the research, polyamide 66 (V-Creamid A3H2), supplied by PTS Plastic Technologie Service, Adelshofen, Germany was used. The material is radiation cross-linkable due to the modification by $3 \mathrm{wt} \%$ of the triallyl isocyanurate (TAIC) cross-linking agent. Injection molding was used to process the cross-linkable material into plate-shaped specimens with a size of $150 \mathrm{~mm} \times 68 \mathrm{~mm} \times 4 \mathrm{~mm}$. The specimens were filled through a film gate and produced with an Arburg 370 injection-molding machine (Arburg $\mathrm{GmbH}+\mathrm{CoKG}$, Loßburg, Germany) at a mold temperature of $80^{\circ} \mathrm{C}$, a melt temperature of $275^{\circ} \mathrm{C}$ and an injection speed of $100 \mathrm{~cm}^{3} \cdot \mathrm{s}^{-1}$. The test specimens were cut and fi-
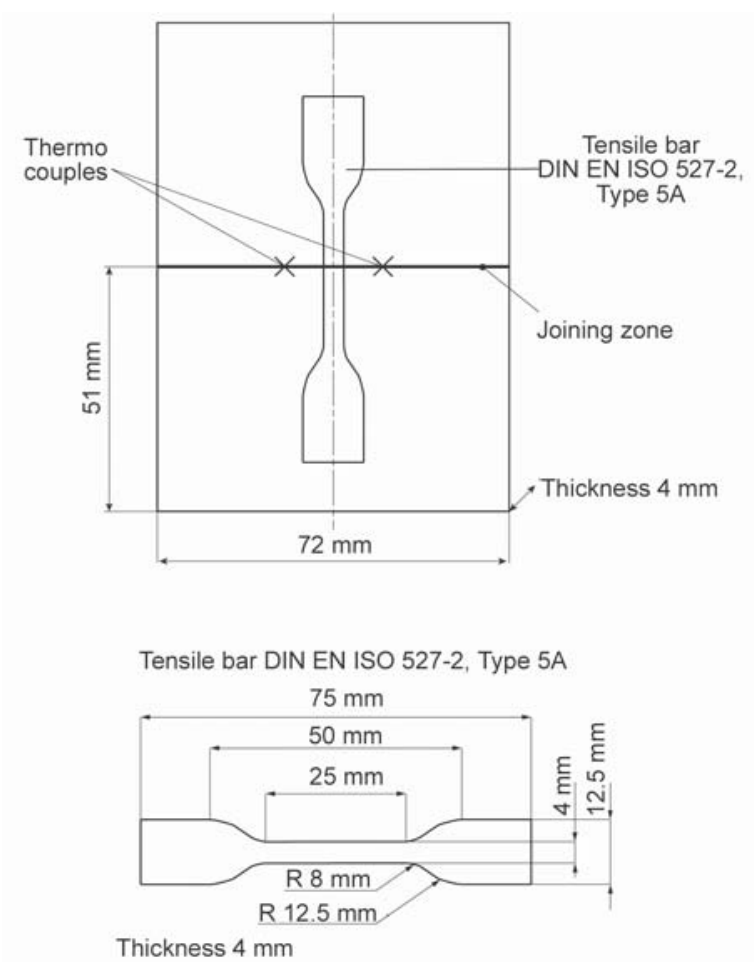

Figure 2. Dimensions of two welded test plates, places of sampling for mechanical investigations and dimensions of tensile bar

nally milled out of the plates, Figure 2 . The joining zone was milled to get a flat surface and a uniform sample height of $51 \mathrm{~mm}$. To avoid moisture absorption and a contamination of the surface, the plates were sealed separately in a vapor proof foil. These plates were exposed to electron irradiation with a $10 \mathrm{MeV}$ electron accelerator. The radiation doses were 33 and $99 \mathrm{kGy}$. To exceed the radiation dose of $33 \mathrm{kGy}$, the electron radiation treatment was performed repeatedly, each with a dose of $33 \mathrm{kGy}$, in order to minimize the thermal load. Tests were also carried out on non-cross-linked material, which is termed $0 \mathrm{kGy}$ in the following.

\subsection{Test methods}

\section{Gel value}

The degree to which the polyamide 66 plates were crosslinked was determined by a gel value analysis. With reference to DIN 16892, sections of the test specimens were boiled in a solvent (concentrated formic acid) for six hours, filtered through a glass frit POR 2 (pore size 40-100 $\mu \mathrm{m}$ ) and were subsequently dried. The gel value was determined as the quotient of the mass remaining after boiling and drying and the initial mass of the specimen. For each gel value analy- 
sis, the arithmetic mean and the standard deviation of the gel value from three separate measurements were determined.

\section{Fourier transform infrared spectroscopy (FTIR)}

To determine the optical properties of cross-linked polyamide in infrared wavelength ranges, a Fourier transform infrared spectroscopy (FTIR) analysis was performed with a Nicolet 6700 device from Thermo Scientific Inc. (Waltham, USA).

Transmission of cross-linked and non-cross-linked polyamide was identified between a wavenumber of 550 and $4000 \mathrm{~cm}^{-1}$ (wavelength of 2.5 to $19 \mu \mathrm{m}$ ) based on the attenuated total reflectance (ATR). The polyamide's extinction is defined as the measured transmission as reduced by reflection and absorption.

\section{Infrared welding}

To determine to which extent the material and processing parameters influenced the weld strength, infrared welding tests were conducted. The infrared welding tests were performed on the infrared and linear vibration welding machine Branson M-112HR (Branson Ultraschall, Dietzenbach, Germany). The welding machine is equipped with an inductive sensor to pick up the meltdown. Two, $1.6 \mathrm{~kW}$, mediumwavelength metal foil emitters from Krelus AG (Oberentfelden, Switzerland) were used to heat up the upper and lower samples. The wavelength range was between 2.5 and $8 \mu \mathrm{m}$ (wavenumber 1250 to $4000 \mathrm{~cm}^{-1}$ ). The distance between the samples and IR emitter was $3 \mathrm{~mm}$. To measure the temperature in the weld area, thermocouples Type $\mathrm{K}$ were used. The thermocouples were placed between the two welding plates, Figure 2. After welding, the thermocouples were cut off and new couples were used for the next trial. Simultaneously, measuring the meltdown and temperature during the process facilitates accurately detecting the weld line temperature when the samples come into first contact $\left(T_{\mathrm{c}}\right)$ with one another. This temperature was used to gauge the effect of the different processes and materials on the resulting

Table 2. Welding parameters

\begin{tabular}{|c|c|c|}
\hline Welding partner & $\begin{array}{c}\text { Joining pressure } \\
{\left[\mathbf{N} \cdot \mathbf{m m}^{-2}\right]}\end{array}$ & $\begin{array}{c}\text { Heating time } \\
{[\mathbf{s}]}\end{array}$ \\
\hline PA66 0 kGy/PA66 0 kGy & $3 / 5$ & $10 / 15$ \\
\hline PA66 33 kGy/PA66 33 kGy & $3 / 5$ & $8 / 10 / 12 / 15$ \\
\hline PA66 99 kGy/PA66 99 kGy & $3 / 5$ & $8 / 10 / 12$ \\
\hline
\end{tabular}

temperature before joining. For the initial heating trials, thermocouples in different depths were placed in the welding plate. In the infrared welding tests, the heating time varied between 8 to $15 \mathrm{~s}$ and the joining pressure between 3 and $5 \mathrm{~N} \cdot \mathrm{mm}^{-2}$, Table 2 .

\section{Mechanical testing (tensile test)}

Tensile tests were carried out in accordance with DIN ISO 527-2 [25]. Tensile test bars of type $5 \mathrm{~A}$ according to EN ISO 527 were milled from the welded plates, Figure 2. Each test was performed under standard testing conditions $\left(T=23^{\circ} \mathrm{C}\right.$, relative air humidity: 50\%). Before testing, the specimens were dried to a constant weight at $70^{\circ} \mathrm{C}$ in a vacuum furnace. The tensile strength, strain at break as well as stress at break of 3 samples were recorded. The mean and standard deviation were calculated from these 3 samples. The pull-off speed was $3 \mathrm{~mm} \cdot \mathrm{min}^{-1}$ for all specimens.

\section{Light microscopic investigations}

Light microscopic investigations on welds before and after mechanical testing were performed with an $\mathrm{Ax}$ ioplan light microscope from Carl Zeiss AG (Oberkochen, Germany). In order to avoid any thermal influences on the welds while preparing the specimen, the weld region was cut out of the welded plates (before mechanical testing) and the tested tensile bars with a water-cooled, low-revolution saw.

The microscopic analysis of the specimens was conducted in the transmitted light procedure on $10 \mu \mathrm{m}$ thin cuts. Polarized light was utilized in order to characterize the morphology and geometry of the weld.

\section{Results and discussion}

\subsection{Effect of the radiation dose on the degree of cross-linking}

The electron irradiation of the polymer results in a three-dimensional network of covalent bonds between the macromolecules. With radiation at $33 \mathrm{kGy}$, a gel value of $49 \%$ with a standard deviation of 0.44 is attained. With a higher radiation dose of $99 \mathrm{kGy}$, the gel value increased to $64 \%$ with a standard deviation of 0.62 .

\subsection{Effect of cross-linking on the optical properties of cross-linkable polyamide 66}

The extinction in relation to the wavenumber of crosslinkable polyamide 66 with and without electron 

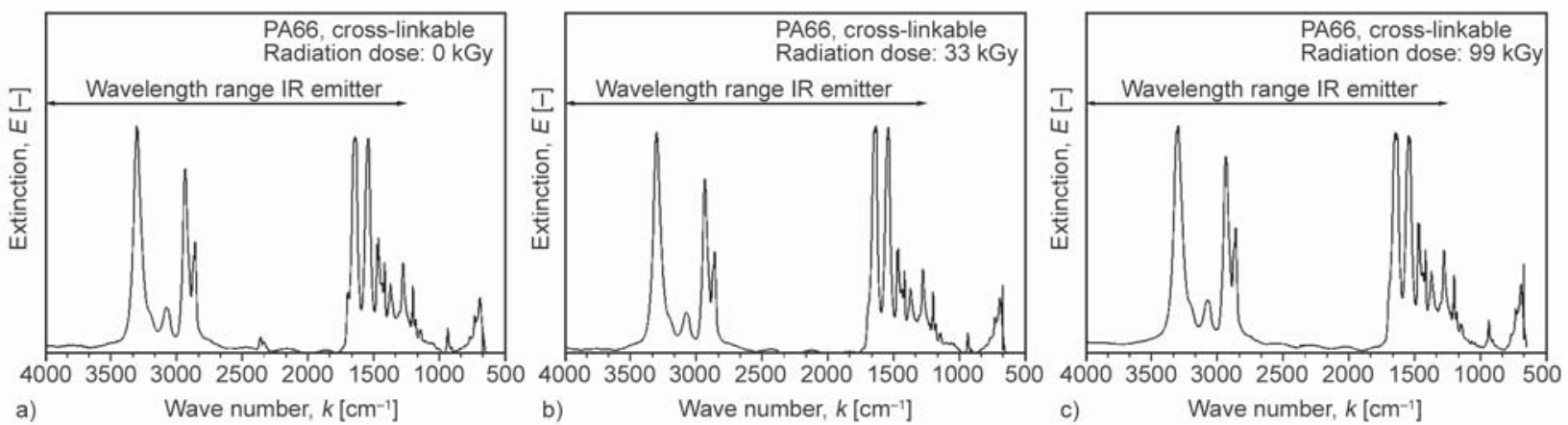

Figure 3. Extinction of radiation cross-linkable polyamide 66 (FTIR), a) radiation dose $0 \mathrm{kGy}$, b) radiation dose $33 \mathrm{kGy}$, c) radiation dose $99 \mathrm{kGy}$

beam irradiation is shown in Figure 3. At around $3000 \mathrm{~cm}^{-1}$, polyamide has the typical characteristic absorption bands for $[C-H]_{\mathrm{n}}$ groups stretching vibrations [23, 24]. Further, the absorption for the bending vibration of the amide group is visible at bands between 1640 and $1550 \mathrm{~cm}^{-1}$ [24]. The peak around $2360 \mathrm{~cm}^{-1}$ could be related to the absorption doublet band of carbon dioxide from the ambient air during the measurement [26]. This peak height may also likely change between measurements and is independent from the tested material. The covalent bonds between the macromolecules do not seem to be IR-active in the wavelength range of a metal foil IR emitter and therefore do not affect the absorption of cross-linkable polyamide 66 or the heating during the infrared welding process.

\subsection{Temperature and meltdown of cross-linkable polyamide 66 during infrared welding}

During infrared heating, the temperature measured in the weld line rapidly increased, as is evident in Figure 4 . The initial peak the first couple of seconds could be attributed to the melting of the non-cross-linked polyamide. At the beginning of the heating process, no melt layer exists and the thermocouples lie on the surface of the weld line. At this position, the measurement can be affected by the environment (e.g. hot air) and lead to an inaccurate weld line temperature. At temperatures above the crystallite melting temperature, a melt layer forms and the thermocouples sink inside the melt. Here, the environmental influences are reduced and the temperature of the molten material can be measured. Inside the molten material the temperature is lower than on the weld line surface. This fact can be seen in the temperature plateauing

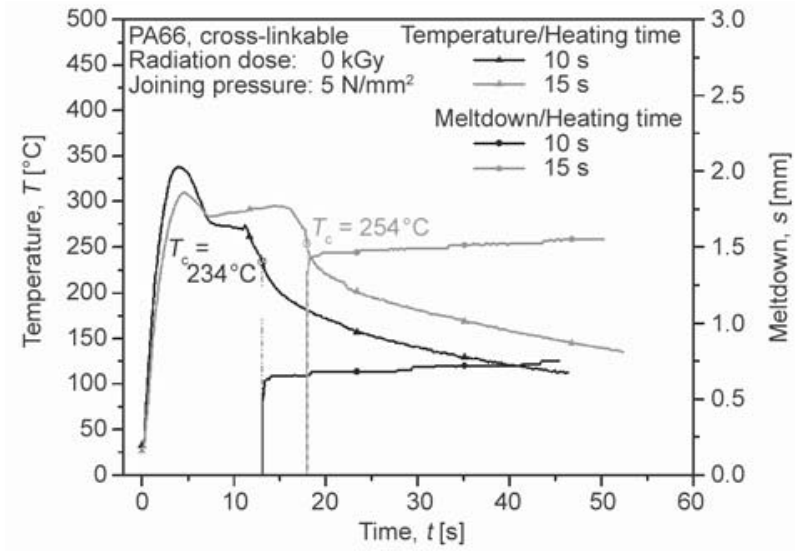

Figure 4. Influence of heating time on temperature in the weld line and meltdown while infrared welding non-cross-linked polyamide 66

before joining. Longer heating times caused the temperature at the moment of joining $\left(T_{\mathrm{c}}\right)$ to rise from 234 to $254^{\circ} \mathrm{C}$. This fact could be explained by the increasing heat energy saved in the molten material. Additionally, longer heating times increased the melt layer's thickness and the resulting meltdown from $0.4 \mathrm{~mm}$ after 10 seconds of heating to $1.4 \mathrm{~mm}$ after 12 seconds.

Cross-linked polyamide 66 showed a rapid increase in temperature within the first seconds, Figures 5 to 8 . The temperature rose over time without any temperature reductions or plateaus as was the case with the non-cross-linked polyamide. This permanent rising of the temperature is also visible in different depths of the material, Figure 5. The temperature on the surface of the weld line is higher and reaches a value of $485^{\circ} \mathrm{C}$. In this stage, the thermocouples on the surface can be affected by the environment and lead to an inaccurate measurement. Therefore the temperature at moment of joining $\left(T_{\mathrm{c}}\right)$ was used to compare the different measurements. In a depth of $0.3 \mathrm{~mm}$, 


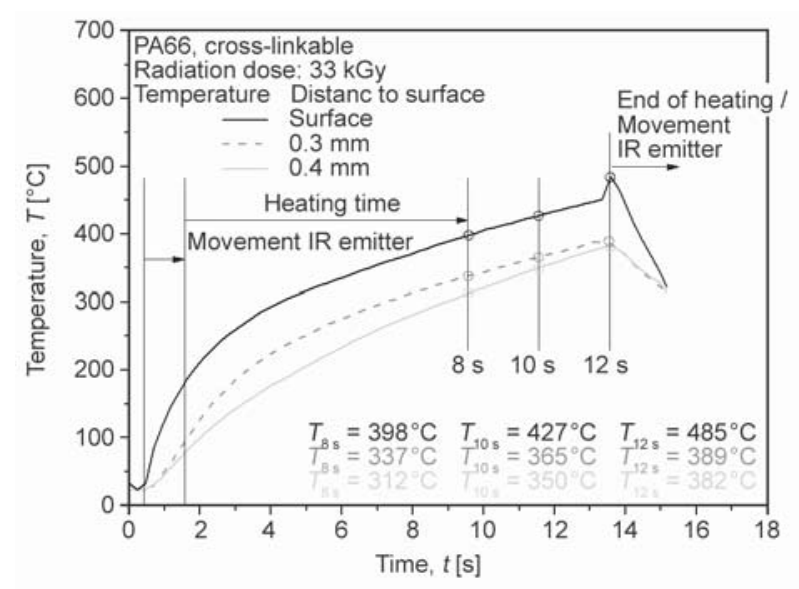

Figure 5. Influence of infrared heating cross-linked polyamide 66 on temperature in the weld zone in different depths

with a minimized impact of the environment on thermocouples, the temperature rose to a maximum of $389^{\circ} \mathrm{C}$. At this temperature a thermal degradation of the material is possible. The convergence of the temperature between 0.3 and $0.4 \mathrm{~mm}$ could be explained with the increasing of the temperature affected area during heating. After the heating, during the movement of the IR emitter, a convergence of the temperature of all three measured depths is visible. After this movement, the temperature at the moment of joining $\left(T_{\mathrm{c}}\right)$ rose from $238^{\circ} \mathrm{C}$ after 10 seconds of heating to $277^{\circ} \mathrm{C}$ after 12 seconds, Figure 6 . The increase in temperature is higher than for non-cross-linked polyamide. This fact could be explained by the rubbery, elastic state of the cross-linked polyamide above the crystallite melting temperature, Figure 1. In this state, the material cannot flow. The cross-linked material remains in its rubbery, elastic state at a distance of $3 \mathrm{~mm}$ between the IR emitter and the sample. This

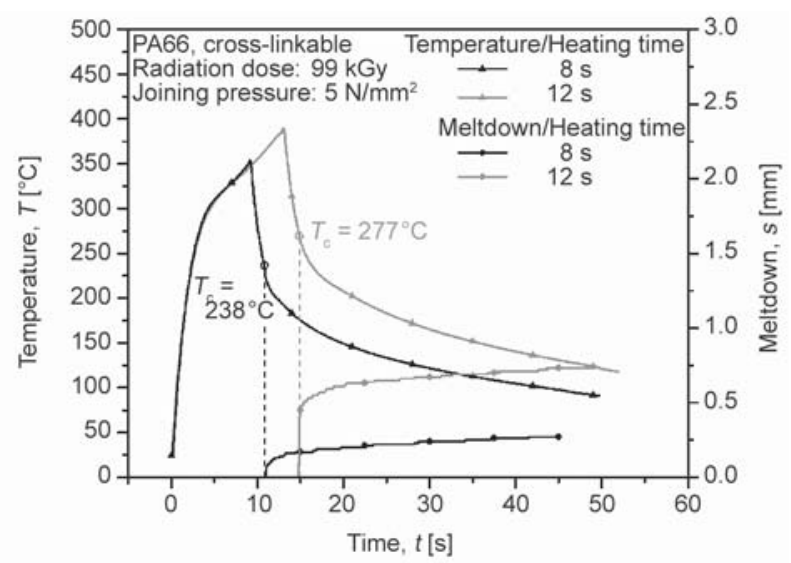

Figure 6. Influence of heating time on temperature in the weld line and meltdown while infrared welding cross-linked polyamide 66 allows energy inputs and resulting temperatures higher than non-cross-linked polyamide at increasing distances based on melt flow. Further, the energy outflow from the melt flow is impeded and the contact with oxygen during the heating could lead to a thermal degradation.

The increased temperature affected areas of the cross-linked polyamide 66 can be estimated with the resulting meltdown, Figure 7. The material has significantly lower mechanical properties (Figure 1) than the base material unaffected by heat and can be squeezed by the joining pressure. Therefore, the meltdown rose with longer heating times, Figure 7 . The squeezing of the material leads also to a stretching of the heated material in the weld line. The maximum stretching is in the middle of the weld line [27]. The gap between the peak temperature and the temperature at the moment of joining $\left(T_{\mathrm{c}}\right)$ is based on the IR welding process. After heating, the IR emitters must be removed between the samples, whereupon the same samples must be pushed together by the joining pressure. During this period, the temperature in the joining area decreases.

As depicted in Figure 8, the radiation dose hardly affected the contact temperature $\left(T_{\mathrm{c}}\right)$ in the weld line. This could be due to nearly equal absorption bands in the wavelength range of the metal foil emitter, Figure 3. The meltdown also showed minimal effects on the radiation dose. This could be attributed to differing residual stiffness in the cross-linked material beyond the crystallite melting temperature being induced by the radiation, Figure 1. The higher sample stiffness with the higher dose of $99 \mathrm{kGy}$ leads to a reduced deformation from the joining pressure. The impact of the

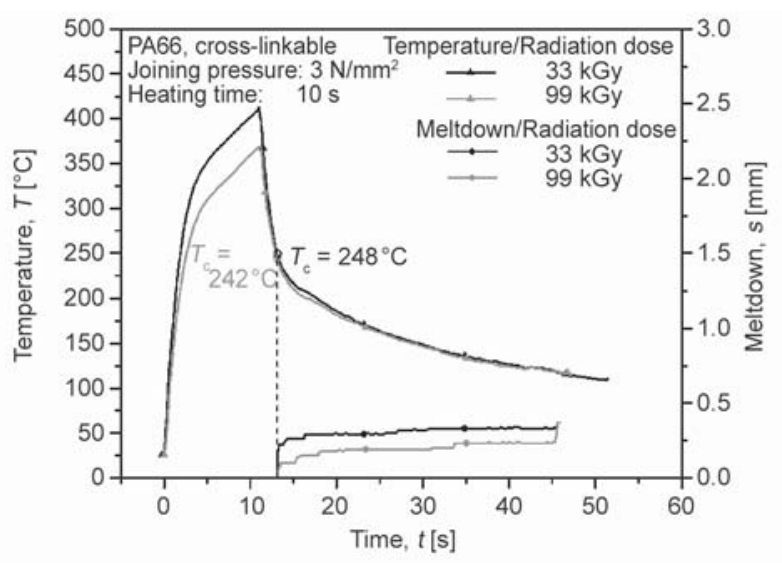

Figure 7. Influence of the radiation dose on temperature in the weld line and meltdown while infrared welding cross-linked polyamide 66 


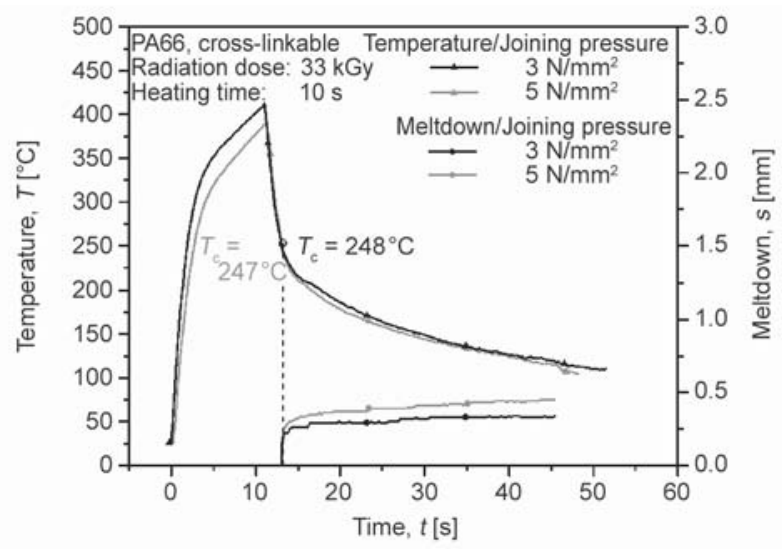

Figure 8. Impact of joining pressure on temperature in the weld line and meltdown while infrared welding cross-linked polyamide 66

joining pressure could also be seen in Figure 8. Higher pressures while joining resulted in an increase in the meltdown. Compared to non-cross-linked polyamide, the measured meltdown is, in general, lower.

\subsection{Weld strength of cross-linkable polyamide 66 from infrared welding}

The representative stress-strain curves from the tensile test on cross-linked polyamide 66 base material
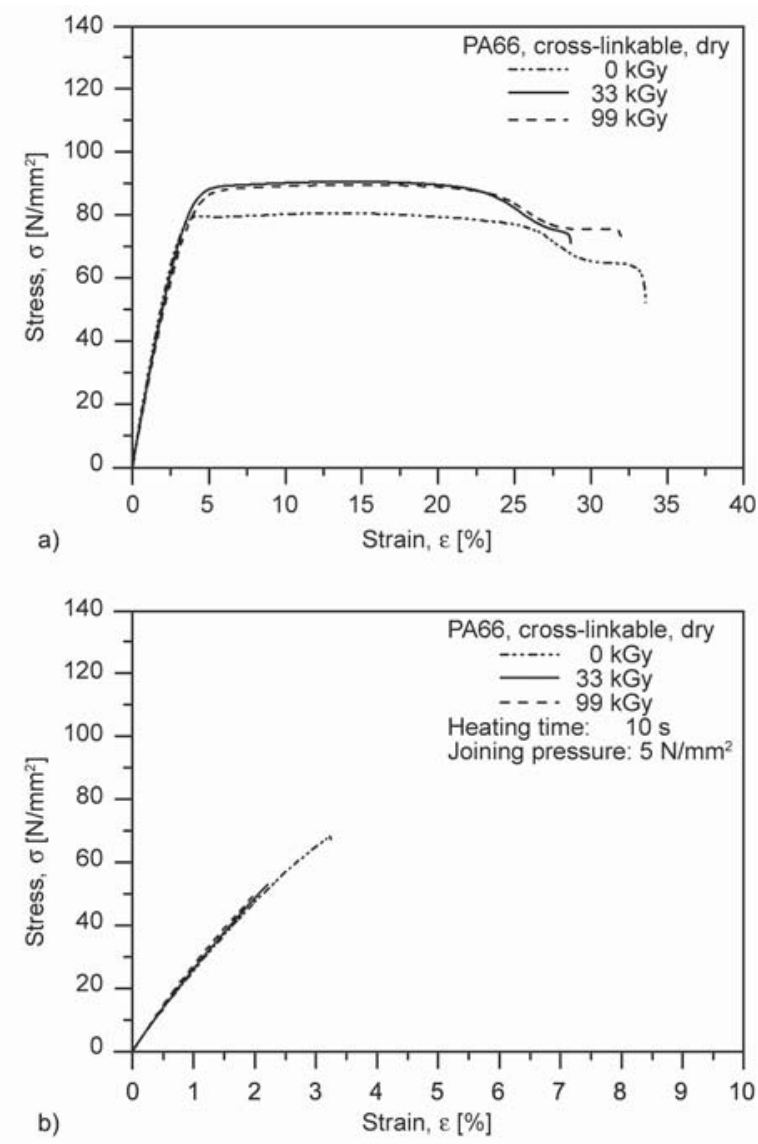

Figure 9. Stress-strain curve of cross linkable polyamide 66: (a) base material, (b) infrared welded samples and the infrared welded samples with no radiation, a dose of $33 \mathrm{kGy}$ and a dose of $99 \mathrm{kGy}$ are shown in Figure 9. The curves of the base material show a ductile mechanical fracture of the samples and the samples without radiation show a lower stress at break. After exposing polyamide 66 to radiation, the base material strength increased from $80.5 \mathrm{~N} \cdot \mathrm{mm}^{-2}$ for the non-cross-linked polyamide to $92.8 \mathrm{~N} \cdot \mathrm{mm}^{-2}$ for the polyamide with a radiation dose of $99 \mathrm{kGy}$, Figure $9 \mathrm{a}$ and 10. Compare to the base material the infrared welded samples show a brittle mechanical fracture, Figure 9b.

The average contact temperature and weld strength attained by the weld specimen in contrast to noncross-linked polyamide 66 and the base material is shown in Figure 10. The resulting weld strength exhibited a dependency on the chosen processing parameters. For the non-cross-linked polyamide 66 , there is no clear correlation between the weld strength, the contact temperature and the processing parameter joining pressure and the heating time, Figure 10.

For the non-cross-linked polyamide with a heating time of 10 seconds and a joining pressure of $5 \mathrm{~N} \cdot \mathrm{mm}^{-2}$, the maximum weld strength was $67 \mathrm{~N} \cdot \mathrm{mm}^{-2}$ with an average contact temperature of $239^{\circ} \mathrm{C}$. In contrast to a lower joining pressure, an increasing joining time led to a small decrease in the weld strength at $65 \mathrm{~N} \cdot \mathrm{mm}^{-2}$ with an increasing average contact temperature of $278^{\circ} \mathrm{C}$. The decrease in the mechanical properties could be attributed to the thermal aging of the material with longer heating times. At higher joining pressures, the aged material is transferred to the weld flash and comes into contact with the unaged material. At lower joining pressures and with shorter heating times, the transfer of the aged material into the weld flash is reduced and

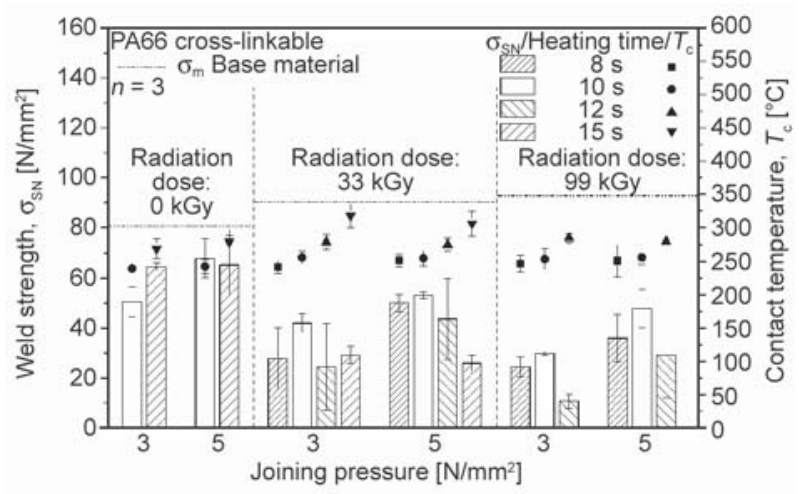

Figure 10. Weld strength and contact temperature of radiation cross-linkable polyamide 66 
the requisite thickness of the melt layer cannot be achieved. Fuhrich indicated that a sufficient melt layer thickness is necessary for a high weld strength [18].

For the cross-linked polyamide 66 , a correlation between joining pressure and the weld strength is evident, Figure 10. With identical heating times, the weld strength increased at higher joining pressures. A reason for the joining pressure affecting the weld strength could be the increase in the joining area, based on the squeeze of the heat-affected material and better surface contact with the joining partner.

For both radiation doses, their maximum strength was at 10 seconds heating time and at an average contact temperature of around $250^{\circ} \mathrm{C}$. Bonten showed for hot plate welding cross-linked polyethylene, that a specific temperature leads to maximum weld strength. An increasing or decreasing of this temperature leads to lower weld strength [28]. The maximum weld strength was $53 \mathrm{~N} \cdot \mathrm{mm}^{-2}$, with a radiation dose of $33 \mathrm{kGy}$ and a joining pressure of $5 \mathrm{~N} \cdot \mathrm{mm}^{-2}$. For $99 \mathrm{kGy}$, the maximum weld strength was $48 \mathrm{~N} \cdot \mathrm{mm}^{-2}$. An increasing heating time led to the weld strength decreasing. These weld strengths are lower than the results of vibration welding radiation cross-linked polyamide 66 . In these investigations weld strength up to $86 \mathrm{~N} \cdot \mathrm{mm}^{-2}$ have been achieved [7]. An explanation for this decrease in the weld strength of infrared welded cross-linked polyamide 66 could be the thermal aging of the material. Figure 6 shows in the heat affected zone a temperature of $389^{\circ} \mathrm{C}$ after a heating duration of 12 seconds. This temperature could cause a thermal ageing of the material, especially in conjunction with the oxygen on the surface. In contrast to the non-cross linked polyamide 66 , the aged material transferring out from the weld line due to the squeeze flow is impeded. With longer heating times, the aging in the weld line increases and could lead to worse adhesion between the joining partner. A higher radiation dose with possible degradation, chain scission or oxidation could enhance the effect of thermal aging.

\subsection{Morphology of the weld of cross-linkable polyamide 66 from infrared welding}

The results from the light microscope investigations into radiation cross-linked polyamide 66 that had been welded are shown in Figure 11 and Figure 12.

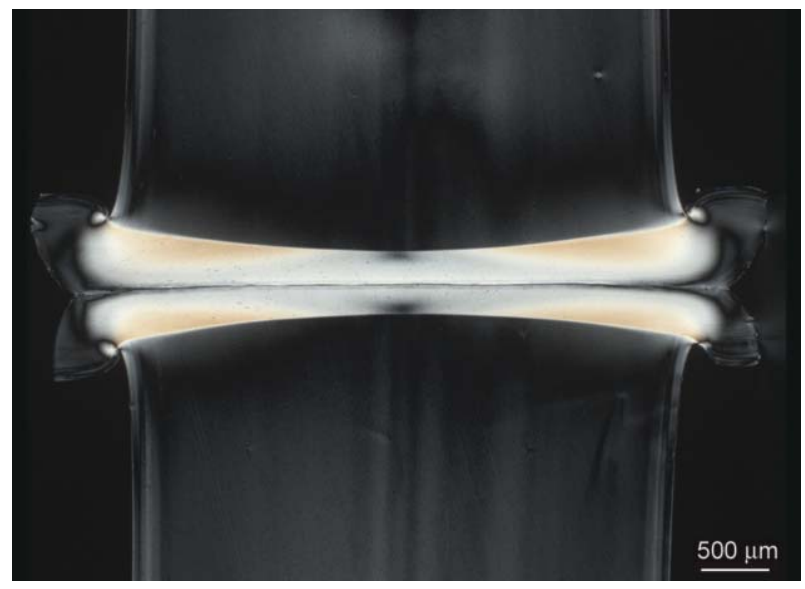

Figure 11. Transmitted light microscopy upon welding radiation cross-linkable polyamide 66 (photographs' conditions: linearly polarized light, polarization axes in the depicted image at $45^{\circ}$ ): IR heating time $10 \mathrm{~s}, 33 \mathrm{kGy}$ (both parts), joining pressure $5 \mathrm{~N} \cdot \mathrm{mm}^{-2}$, weld strength $53.1 \mathrm{~N} \cdot \mathrm{mm}^{-2}$
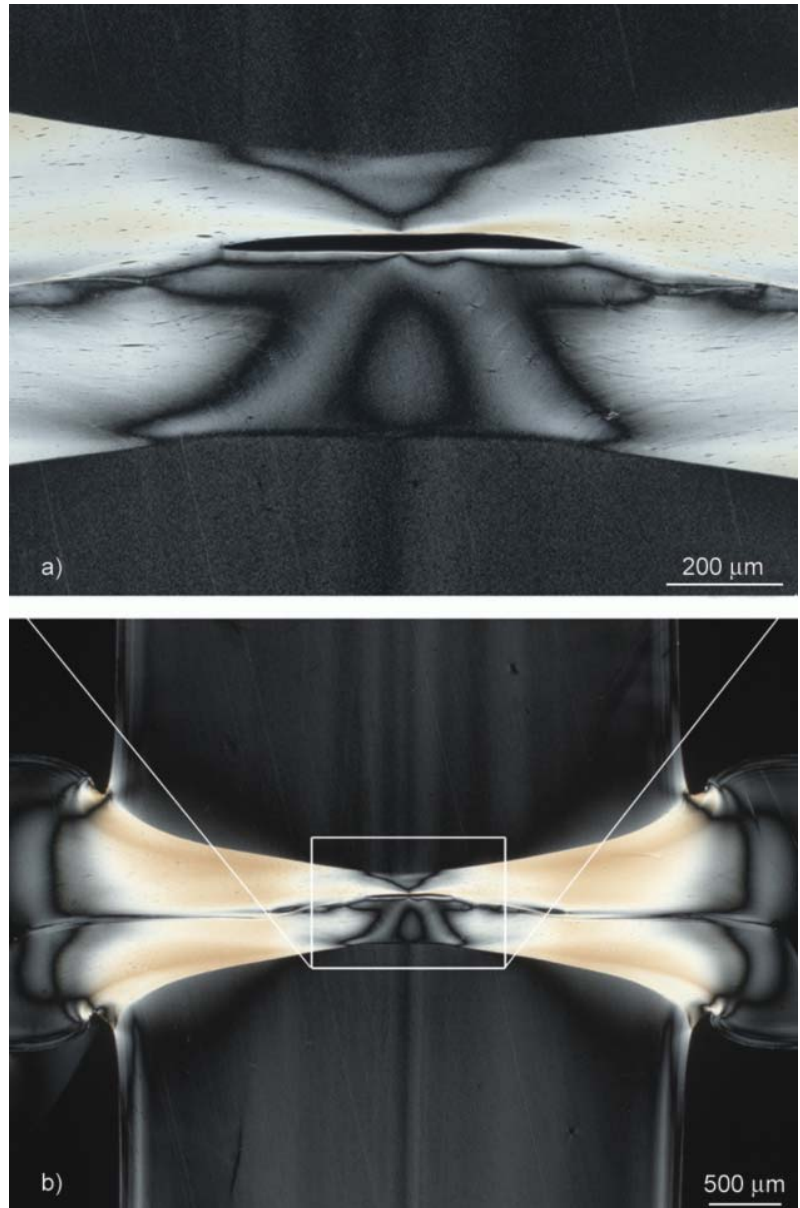

Figure 12. Transmitted light microscopy upon welding radiation cross-linkable polyamide 66 (photographs' conditions: linearly polarized light, polarization axes in the depicted image at $45^{\circ}$ ): IR heating time $15 \mathrm{~s}, 33 \mathrm{kGy}$ (both parts), joining pressure $5 \mathrm{~N} \cdot \mathrm{mm}^{-2}$, weld strength $25.9 \mathrm{~N} \cdot \mathrm{mm}^{-2}$, a) detail view, b) overview 
The light microscopic investigations of the tested samples are shown in Figure 13 and 14. A welded, cross-linked polyamide 66 with a high weld strength of $53 \mathrm{~N} \cdot \mathrm{mm}^{-2}$ can be seen in Figure 11. The birefringent regions originating from the center of the specimen are clearly recognizable. These may indicate orientations of the cross-linked material caused by the squeeze deformation during the joining process. Further, a smooth weld line is visible. In contrast to conventional welds between semicrystalline thermoplastics, no typical flow structures are visible. Figure 12 shows a weld with low weld strength. The size of the heat-affected material with the birefringent region is larger than the size of the sample with 10 seconds heating time and further an increase in the zone towards the edges of the sample is visible. This fact is due to longer heating times and the lateral radiation from the metal foil IR emitter, which results in a

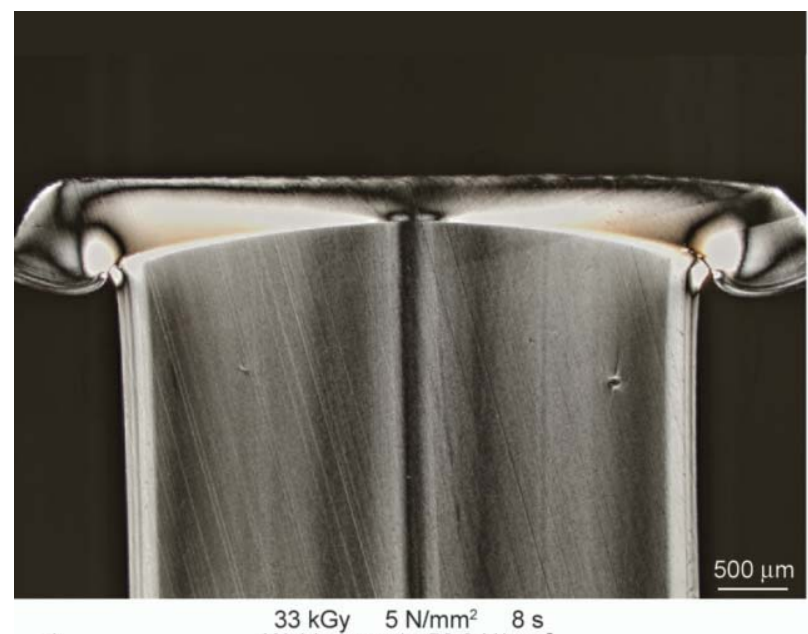

a)

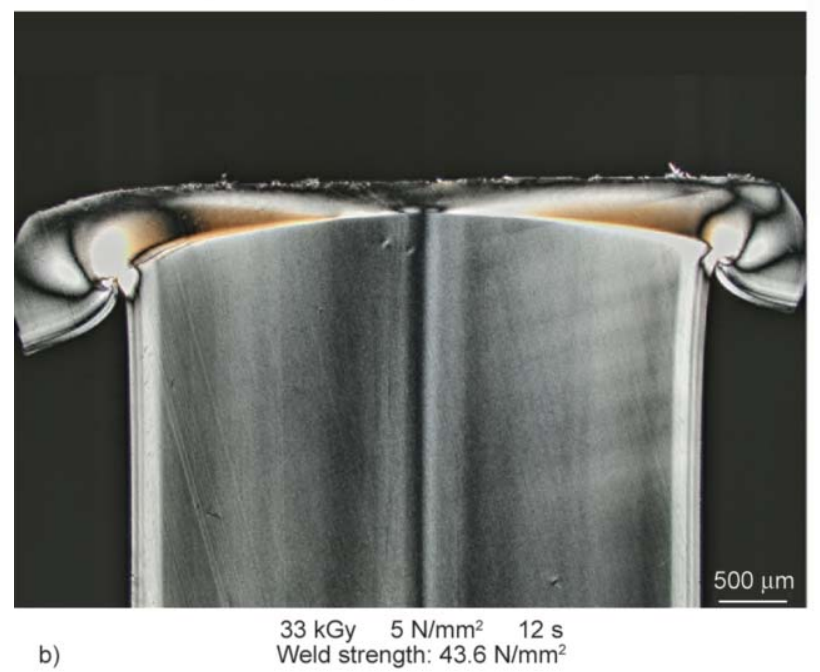

higher energy input particularly around the edges. Additionally, a hole in the wavy weld line is visible. This may be attributed to the longer heating times with the material's resulting aging.

The light microscopy investigations of specimens after the tensile tests are shown in Figure 13 and Figure 14. The position of failure during the test was mostly located in the weld line. For the specimen with the highest and the lowest weld strength a similar fracture surface, with a smooth fracture along the weld line, is visible, Figure 13 and Figure 14. With a higher joining pressure of $5 \mathrm{~N} \cdot \mathrm{mm}^{-2}$ the length of the weld line increased slightly. The notches of the weld seam were probably not a starting point for the fracture of the samples. The specimen with a heating duration of 15 seconds shows a fracture across the temperature affected area.
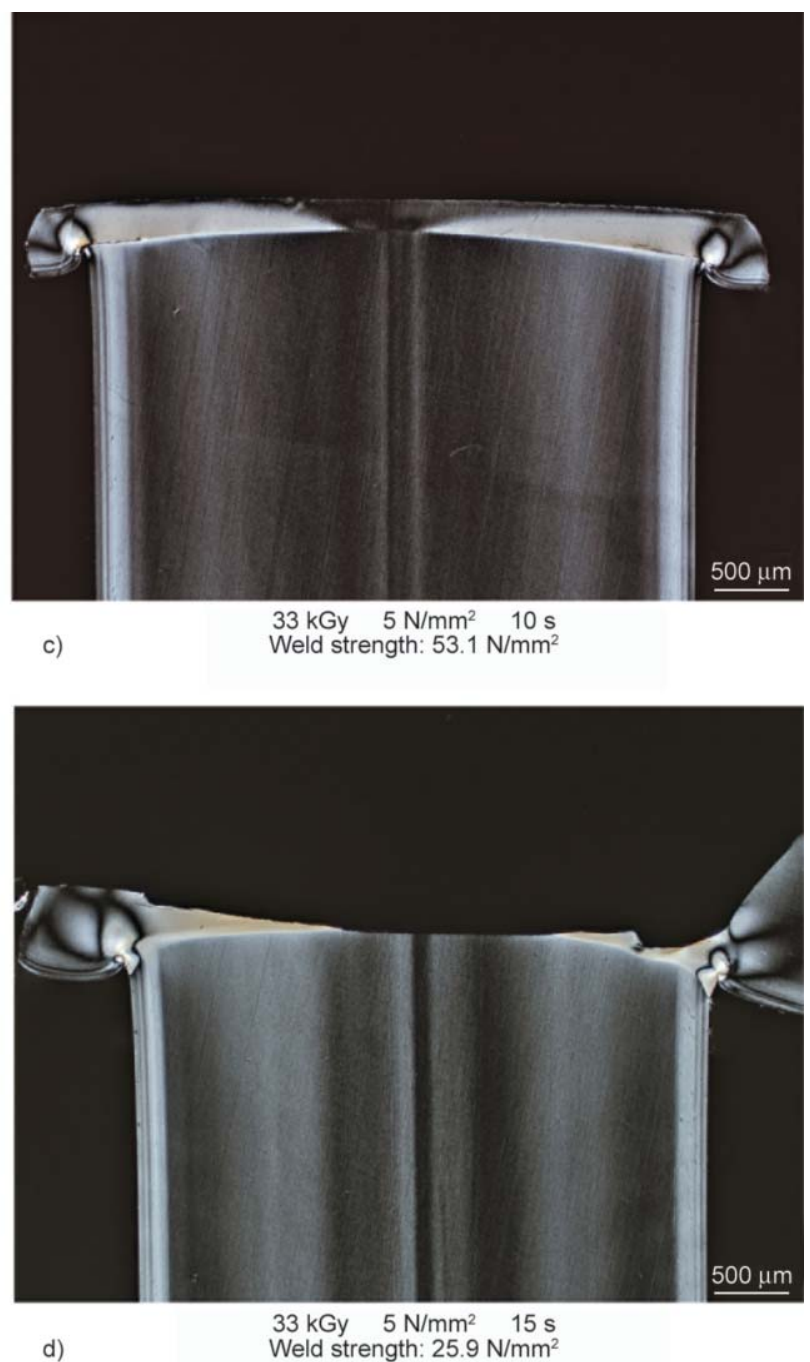

d)

Figure 13. Transmitted light microscopy upon tensile tests of radiation cross-linkable polyamide 66 (photographs' conditions: linearly polarized light, polarization axes in the depicted image at $45^{\circ}$ ), a) $\left.33 \mathrm{kGy}, 5 \mathrm{~N} \cdot \mathrm{mm}^{-2}, 8 \mathrm{~s}, \mathrm{~b}\right) 33 \mathrm{kGy}$, $\left.\left.5 \mathrm{~N} \cdot \mathrm{mm}^{-2}, 12 \mathrm{~s}, \mathrm{c}\right) 33 \mathrm{kGy}, 5 \mathrm{~N} \cdot \mathrm{mm}^{-2}, 10 \mathrm{~s}, \mathrm{~d}\right) 33 \mathrm{kGy}, 5 \mathrm{~N} \cdot \mathrm{mm}^{-2}, 15 \mathrm{~s}$ 


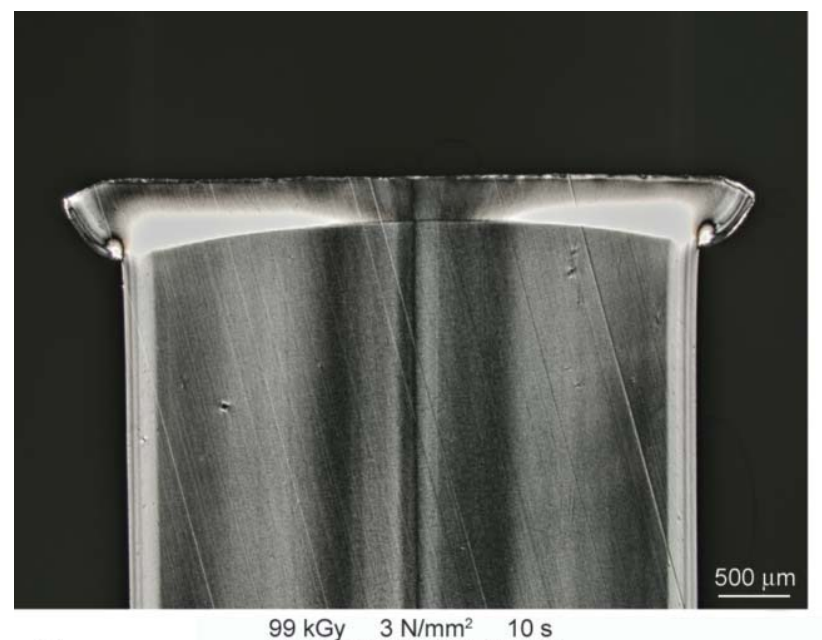

a)

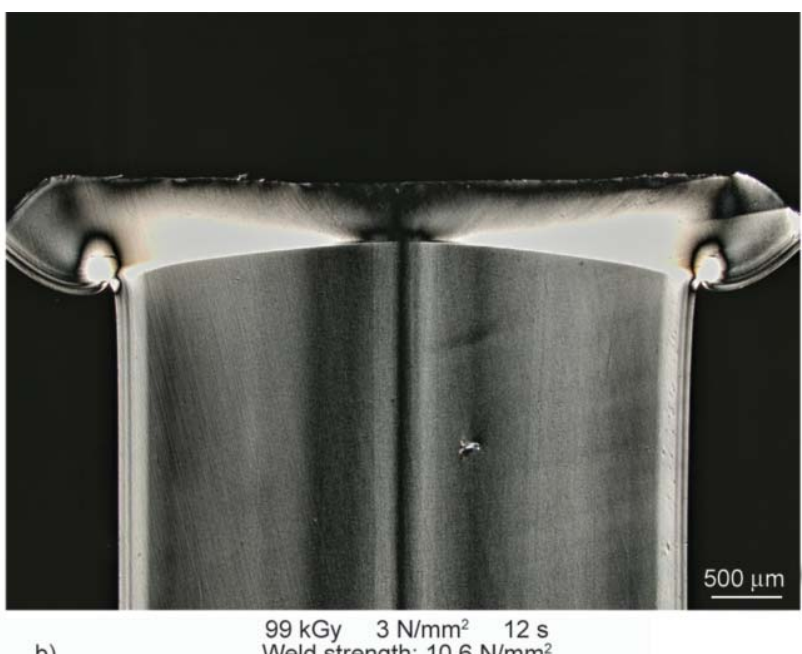

b)
$99 \mathrm{kGy} \quad 3 \mathrm{~N} / \mathrm{mm}^{2} \quad 12 \mathrm{~s}$

Weld strength: $10.6 \mathrm{~N} / \mathrm{mm}^{2}$

Figure 14. Transmitted light microscopy upon tensile tests of radiation cross-linkable polyamide 66 (photographs' conditions: linearly polarized light, polarization axes in the depicted image at $45^{\circ}$ ), a) $\left.99 \mathrm{kGy}, 3 \mathrm{~N} \cdot \mathrm{mm}^{-2}, 10 \mathrm{~s}, \mathrm{~b}\right) 99 \mathrm{kGy}$, $3 \mathrm{~N} \cdot \mathrm{mm}^{-2}, 12 \mathrm{~s}$

\section{Conclusions}

The results obtained within the framework of the present research show that radiation cross-linking significantly affects the processing characteristics of infrared welding.

Electron beam irradiation led to no significant changes in the absorption bands in the wavelength range of a metal foil IR emitter but to alterations in the softening behavior above the crystallite melting temperature toward a rubber, elastic state. This state prevents squeeze flow during heating and, thus, led to the IR emitter exerting an altered energy input into the weld line. The energy outflow was impeded by the lack of squeeze flow and the material remained at a constant distance from the IR emitter during infrared heating. This is in contrast to the non-cross-linked polyamide with an increasing distance from the IR emitter, based on the melt flow.

For the cross-linked polyamide, the weld temperature showed a steady increase throughout the joining process and reached temperatures above the crystallite melting temperature. The resulting contact temperature increases with the heating duration. The meltdown proved to depend on the cross-linking-induced residual stiffness above the crystallite melting temperature and the heating time and joining pressure of the welding process. At higher radiation doses, the degree of cross-linking, and thereby the residual stiffness, increased. This stiffness emerging within the heat-affected material led to a different meltdown. With lower rates of cross-linking-induced residual stiffness, longer heating times, and higher joining pressures, the meltdown during the joining process increased. With a higher joining pressure the length of the weld line increases slightly and thus the possible joining area. Of the investigated parameters, heating duration and the resulting contact temperature exhibited a significant effect on the weld strength.

If the heating time was too short and the contact temperature was low, the specimens reflected lower values. Conversely, if the heating time was too long, the weld strength would also decrease. Around a heating time of 10 seconds, the maximum weld strength for the chosen process parameters was reached. A possible explanation for this effect could be thermal aging. The specimens with a longer heating duration exhibited a temperature which could lead to oxidative degradation of the material and subsequently to lower mechanical properties of the cross-linked material. Further investigations should explore this claim.

\section{Acknowledgements}

The authors would like to thank the German Research Foundation (DFG) for funding this work within the project DR 421/13-1 'Bonding mechanism during welding of radiation cross-linked thermoplastic polymers'. The authors are also grateful to PTS Plastic Technology Service, Adelshofen, Germany, for providing radiation cross-linkable polyamide 66 and BGS Beta Gamma Service, Bruchsal, Germany, for the electron beam irradiation. 


\section{References}

[1] Makuuchi K., Cheng S.: Radiation processing of polymer materials and its industrial applications. Wiley, New Jersey (2011).

[2] Heger A., Dorschner L., Dunsch L.: Technologie der Strahlenchemie von Polymeren. Hanser, München (1990).

[3] Seefried A.: Zum Thermoformen von vernetztem Polyamid. PhD Thesis, Friedrich-Alexander-Universität Erlangen-Nürnberg, Erlangen (2015).

[4] Chapiro A.: XII ${ }^{\text {th }}$ international meeting on radiation processing Avignon 25-30 March 2001 (Polymer irradiation: Past-present and future). Radiation Physics and Chemistry, 63, 207-209 (2002).

DOI: $10.1016 / \mathrm{S} 0969-806 \mathrm{X}(01) 00621-1$

[5] Heinze D.: Das Verhalten von Hochpolymeren gegenüber energiereicher Strahlung. Kolloid-Zeitschrift und Zeitschrift für Polymere, 210, 45-54 (1966). DOI: 10.1007/BF01500434

[6] Charlesby A.: Atomic radiation and polymers. Pergamon Press, Oxford (1960).

[7] Leisen C., Menacher M., Drummer D.: Influence of radiation cross-linking of polyamide 66 on the characteristics of the vibration welding process. Polymer Engineering and Science, 55, 2493-2499 (2015). DOI: $10.1002 /$ pen.24139

[8] Seefried A., Drummer D.: Thermoforming radiation crosslinked polyamide - Effects of degree of cross linking and thermoforming processing conditions. in 'Proceedings of the $72^{\text {nd }}$ Annual Technical Conference of the Society of Plastics Engineers, Las Vegas, USA' Vol 72, 2400-2407 (2014).

[9] Drummer D., Seefried A.: Thermoformability of radiation cross linked polyamide 12 . in 'Proceedings of the $69^{\text {th }}$ Annual Technical Conference of the Society of Plastics Engineers: The Plastics Conference, Boston, USA' Vol 69, 2520-2526 (2011).

[10] Lee D. W.: Permanent vernetzt - Elektronenstrahl-Vernetzung von PA und PBTP. Kunststoffe, 91, 78-80 (2001).

[11] Bernstein B. S., Odian G., Orban G., Tirelli S.: Radiation crosslinking of nylon 66 and poly(vinyl alcohol). Journal of Polymer Science Part A: Polymer Chemistry, 3, 3405-3412 (1965). DOI: $10.1002 /$ pol.1965.100031004

[12] Brocka Z.: Werkstoff- und Einsatzpotential strahlenvernetzter Thermoplaste. PhD Thesis, Friedrich-Alexander-Universität Erlangen-Nürnberg, Erlangen (2008).

[13] Wiedmer S., Gellner D., Friedrich K.: Effect of electron-beam radiation on thermoplastic composites. Plastics, Rubber and Composites, 34, 76-84 (2005). DOI: $10.1179 / 174328905 X 48568$
[14] Leisen C., Seefried A., Drummer D.: Post-cross-linking behavior of radiation cross-linked polyamide 66 during vibration welding. Polymer Engineering and Science, in press (2016).

DOI: $10.1002 /$ pen.24300

[15] Ehrenstein G. W.: Handbuch Kunststoff-Verbindungstechnik. Hanser, München (2004).

[16] Lambiase F., Paoletti A., Di Ilio A.: Mechanical behaviour of friction stir spot welds of polycarbonate sheets. The International Journal of Advanced Manufacturing Technology, 80, 301-314 (2015). DOI: $10.1007 / \mathrm{s} 00170-015-7007-4$

[17] Paoletti A., Lambiase F., Di Ilio A.: Analysis of forces and temperatures in friction spot stir welding of thermoplastic polymers. International Journal of Advanced Manufacturing Technology, 83, 1395-1407 (2016). DOI: $10.1007 / \mathrm{s} 00170-015-7669-y$

[18] Fuhrich R.: Infrarotschweißen von Kunststoffen mit thermischen Strahlungsemittern. Verlag Dr. Hut, München (2013).

[19] DIN 5030-2: Spectral measurement of radiation; radiation sources; Selection criteria (1982).

[20] DIN EN 62798: Industrial electroheating equipment Test methods for infrared emitters (2015).

[21] DIN EN 60519-12: Safety in electroheating installations - Part 12: Particular requirements for infrared electroheating installations (2014).

[22] Gehde M., Friedrich S., Motchev S.: Strahlungserwärmung beim Kunststoffschweißen mit Infrarotstrahlung. Joining Plastic - Fügen von Kunststoffen, 1, 58-63 (2008).

[23] Heil M.: Heizstrahlerschweißen thermoplastischer Kunststoffe. PhD Thesis, Universität Gesamthochschule Paderborn, Paderborn (1994).

[24] Lin-Vien D., Colthup N. B., Fateley W. G., Grasselli J. G.: The handbook of infrared and Raman characteristic frequencies of organic molecules. Academic Press, London (1991).

[25] DIN EN ISO 527-2: Plastics - Determination of tensile properties - Part 2: Test conditions for moulding and extrusion plastics (2012).

[26] Gottwald W., Wachter G.: IR-Spektroskopie für Anwender. Wiley-VCH, Weinheim (1997).

[27] Menacher M.: Vibrationsschweißen von strahlenvernetztem Polyamid 66. PhD Thesis, Friedrich-Alexander-Universität Erlangen-Nürnberg, Erlangen (2015).

[28] Bonten C.: Contribution to an explanation of the acting mechanism in welded seams out of semicrystalline thermoplastics. Shaker Verlag, Aachen (1999). 